\title{
Study on the Countermeasures of Forest Protection and Utilization Based on Sustainable Development
}

\author{
Jianwei Zheng \\ Hebei Agricultural University, Baoding Hebei, 071001, China
}

Keywords: Sustainable development, Forest protection, Utilization, Countermeasures.

\begin{abstract}
The concept of sustainable development has certain scientific characteristics, in the social and economic level gradually increased, the concept can penetrate into various fields. Especially in China's forest protection work, its protection and utilization period, to promote sustainable construction, to achieve forest protection and management, to ensure the effective use of resources.
\end{abstract}

\section{Introduction}

Forests are more complex on earth, have more functions, can achieve a stable ecosystem, the people's active development has an important role. At the same time, the forest also has a high economic value and ecological value, in recent years, with the continuous use of environmental resources, resulting in a serious phenomenon of climate warming, so the protection and management of forest resources has a very important role.

\section{The Characteristics of Forest Resources in China}

China has a larger geographical area, the existence of the natural conditions are more complex. For China's forestry resources, containing coniferous forest, deciduous broad-leaved mixed forest, deciduous broad-leaved forest, the forest accounted for $69.62 \%$ of the total area. In recent years, China's forest area, accumulation to maintain the growth rate can be increased. Its main features are:

First, the total amount of forest resources there is a large shortage, the existence of the lower coverage, not only the per capita possession of small, the overall quality of the forest is not high.

Second, the distribution of forest resources in China, there is a large imbalance. Because of the natural conditions, historical elements and the unbalanced development of social and economic factors such as the impact of China's forest resources there is a large distribution of imbalance. Among them, in the northeast of China, southwest there is a centralized forest, accounting for $41.27 \%$ of the total. The rest is in the southern region of our country. For the western region of China, due to the extremely fragile ecological environment, the environment needs to be changed, and the forest resources are also less. Therefore, China's forest structure is irrational, its quality is not strict enough, on the whole, by the impact of natural disasters, more frequent elements.

Third, with the economic growth of forest enhancement, there is lack of material forest. Mainly the quality of some economic forest cultivation is not enough, a variety of new varieties missing serious. Some forest resources in the upper reaches of the Yangtze River and mountains, as an important protection area, with the conservation of natural forests in recent years, the implementation of the number of forest resources protection there are still large restrictions.

Fourth, the forest structure is not reasonable; the overall quality is not high. In the forest, some species are few, especially the shelter forest, special forest, in some areas there are serious young forest harvesting phenomenon, affecting the forest post-cultivation work. 


\section{Problems in the Protection and Utilization of Forest Resources in China}

China's forest resources, the overall number of relatively small, especially in some secondary forests, virgin forest, the growth of these forests is relatively slow, in the ecological environment improvement and economic and social development, can not provide good protection, but also sustainable development there is a large difference. The overall number of forest resources is insufficient, there are still serious damage phenomenon, its protection is not enough, compared with the growth rate, there are still large differences. Under the gradual improvement of China's economic level, the demand for forest resources is relatively large, but to a certain extent, the protection consciousness of our people is relatively weak, the concept is more backward, resulting in the protection and utilization of forest resources, there is a greater difficulty The In no hurry, there will be some chaos cut off, casually reclamation and destruction of forest resources, so as to cause greater harm to the ecological environment under normal circumstances, mainly for the following aspects.

First, people only pay attention to short-term economic benefits, during the harvest, did not follow the approved provisions and standards. For some areas of the forest, there is a high price, will lead to the use of various means to harvest.

Second, some of the woodland was developed and utilized, leading to a greater use of the area. In order to improve the regional economy and promote the speed of its development, began to develop forest resources to ensure that tourism resources, forest villas and other attractions, the forest land into non-forest land, resulting in serious damage to the whole forest.

Third, on the whole, the quality of the forest is declining and more serious. Forest benefits and the quality of the forest has a very important role, relying on quality, in order to achieve efficiency.

China gradually attach importance to the protection of forest resources, in recent years, to strengthen the formation of various laws and regulations, for the development of the relevant protective measures. However, in some areas, in order to achieve short-term benefits, there is no recognition of the relationship between economic development and forest resource protection, resulting in some illegal acts and reducing the sustainable development of the country. In the process of protecting the forest resources, the most important factor is that the management system established in our country is not perfect, the division of responsibilities of the staff is not obvious, the technology used is relatively backward, can not meet the protection and management needs of modern forest resources. At the same time, some departments did not form the correct concept, resulting in the use of measures in the work is only a form, in the specific implementation, not in accordance with the relevant provisions of China and related systems to its planning, its monitoring, thus reducing the harvesting work Normative. Second, the forest resources property rights is not clear enough, the use of the management system is not reasonable, especially in some mountains, can not be its supervision and management, so that in order to safeguard the country's economic efficiency and regional benefits, need to focus on the protection of forest resources, Its monitoring and management, and promote the optimization of forest resources protection work to ensure that under the long-term development, the consumption of its resources, inhibit the consumption of forest resources.

\section{Forest Protection and Utilization Countermeasures Based on Sustainable Development}

\section{Establish the concept of sustainable management}

According to China's actual development, fully learn from the concept of advanced forest management to ensure the formation of sustainable management concepts [1]. The formation of sustainable management concept mainly protects the forest ecosystem structure, promotes the integrity and function of its use, ensures the system's circular balance and the full utilization of forest resources, and the combination of ecological and economic benefits. Diversify functions and efficiently use forest resources. The concept of sustainable concept is mainly for the forest of various values, mainly reflected in the economic, ecological, social and other aspects of the maintenance of biological diversity, to achieve ecological and environmental protection work is of great significance. 
Therefore, in the protection of forest resources, we must make it meet people's development needs, for future generations to provide adequate conditions for forest resources. The full application of sustainable concepts to the development process can promote the sustainability of structures, functions, status and development and utilization. Therefore, the concept of sustainable development of forests needs to develop the system, to promote its more efficient, to achieve the comprehensive development and utilization of forest resources.

\section{Improve forest legal system construction}

Strengthen the construction of forest legal system, to develop scientific and reasonable policies and regulations system, and promote the rationalization of forestry resources. Based on the policy, to achieve a certain degree of guidance and regulation, use laws and regulations to regulate the various industries to ensure that all sectors of society can participate in forestry construction and reduce the sustainable development of the various elements. Economic and legal as the main means of application, can promote the effective management of forestry work. Such as: the use of tax policy, finance, price and other economic factors, industrial policy, the optimal adjustment of the interests of the structure, so as to ensure the stability of resource efficiency. Such as: the development of ecological tax policy to promote the use of resources to enhance efficiency, during which you can establish a sound system of laws and regulations for the sustainable development of an effective integrated mechanism. It is possible to follow the strict implementation principle of the forest resources, and strictly control the quantity and consumption of forest harvesting, ensure the good implementation of all aspects of the approval work, and promote the optimization of the mechanism so as to ensure the effective work Supervision, strict management [2].

\section{Establish a scientific system of property rights}

To establish a scientific and reasonable property right system for forest resources, it is necessary to follow the stage of paid use of forest resources in the specific implementation work, to develop the compensation for the use and circulation of forest resources property rights, to promote the standardization of ownership and use rights, but also to realize Paid transfer, forest resources, asset management, in accordance with the relevant provisions of the forest assets to conduct an effective assessment. At the same time, we should also issue and manage forest warrants, strengthen the full use of forest rights, ensure that all personnel in the maintenance of rights and interests on the basis of promoting property rights to achieve a legitimate legal rights and interests of forest resources is a reasonable harvest. Based on the law, because it is the difference between the forest resources related departments and the rights management personnel, it is necessary to define the relationship so as to ensure that the ownership can be handled correctly. To achieve the right of the right to operate and the right to act on behalf of the normative, based on the various duties and rights, to ensure that the implementation of the supervision mechanism more perfect [3].

\section{Improve the legal system of ecological benefits compensation}

The establishment of forest ecological benefits compensation legal system, during which to be based on it. Because the forest resources with high economic and social benefits, to maintain the social and ecological environment. Such as: forest resources can play a wind and sand, the role of dust, so the management of forest construction work, need to invest some money. The ecological characteristics of the forest have certain external characteristics. The external features also need internalization and economic compensation of forest ecological benefits, which can provide suggestions for the sustainable development of forest resources. And, but also reasonable to clear the way to raise funds for compensation, not only to the state and local funds, but also the implementation of "who benefit, who compensation" development principles, to ensure that individuals, social subjects can pay the corresponding share. At the same time, the analysis of ecological compensation object, the scope of compensation and compensation standards, China's focus on nature reserves, shelter forest implementation requirements, the need for forest ecological compensation funds as the main remedial object, so for the development of relevant standards, to analyze the forest Area, the quality of forests 
and the ecological functions of forests, etc., to ensure that people have a greater degree of recognition, to achieve sustainable development. Finally, promote the feasibility of ecological compensation inspection and supervision mechanism. Ecological compensation funds have a certain pertinence, mainly on the implementation of forest construction, planning and protection work. Among them, the effective supervision work for the main part of the need for forest ecological benefits, capital implementation and financial compensation work to monitor and inspect, to ensure the effective operation of forest ecological benefits.

\section{Strengthen pest control work}

Strengthen the forest pest control work, the forest environmental pollution and the phenomenon of forest resources to effectively control the destruction. Because pests and diseases will make forest resources have a greater harm, so we must use the relevant measures to prevent them to ensure that the forest can grow in a good environment, promote sustainable progress and development. And, because the city has a large number of air pollution phenomenons, by the impact of acid rain phenomenon, so be sure to control its pollution [4].

\section{Crack down on illegal trading}

For some illegal trading of wood, wood products should strict blow. During the period, it is strictly forbidden to hunt in the forest area, the protection of some wild animals and plants to reduce its damage to forest resources. But also increase the intensity of some illegal personnel to achieve accountability, the use of punishment to its control. Forest is also the main living area of animals and plants, is the most active areas of the earth, with the diversity of biological development, the rational protection of resources, we must prohibit some people to the forest area hunting, reduce the destruction of resources, promote the protection of the region So as to achieve the sustainable use of forest resources [5].Strengthen education and publicity

The forest protection work to actively promote and expand public participation. Under the development of today's world, according to the theory of nature and methods, promote the formation of advanced forestry theory, to ensure that the cultivation of the forest to meet the natural and scientific development. In recent years, China has a large area of introduction and afforestation work, according to the construction standards of the forest to promote the evaluation of the effectiveness of the work, but to a certain extent, its existence is low, and environmental development is not enough harmony, cannot achieve forest resources Continuous operation. Therefore, in this way, need to correctly understand the forest with the versatility and nature, to ensure that the full realization of the value of forest resources, the expansion of the scope of the available forest. Under such conditions, the relevant methods need to achieve the natural development of resources. Such as: to strengthen education and propaganda work, the concept of forest protection, maintenance of ecological balance awareness into the work of youth education, so that it has a positive impact in society. But at present, in the forest education propaganda work is still relatively backward, the use of methods and means are relatively simple. Therefore, in order to promote the sustainable construction and development of China's forestry, it is necessary to attract the attention of the public, especially for young people to educate the public, and strive to improve people's awareness of ecological protection. Such as: the use of television, multimedia and other media to promote and improve the work of forest protection to ensure that China's forestry resources to speed up the full use and effective protection.

\section{Conclusions}

The effective use and protection of forest resources can promote the promotion of social and economic level and the reasonable adjustment of natural climate, which plays an important role in the development of modern society. Therefore, to achieve effective forest protection work and management, we must according to China's actual development, to ensure the combination of economic and ecological environment, to achieve sustainable progress. 
The effective use and protection of forest resources can promote the promotion of social and economic level and the reasonable adjustment of natural climate, which plays an important role in the development of modern society. Therefore, to achieve effective forest protection work and management, we must according to China's actual development, to ensure the combination of economic and ecological environment, to achieve sustainable progress.

\section{References}

[1] Wang Dexue. How to Deal with the Relationship between Forest Management and Sustainable Development, Agriculture and Technology, 2014(8):72-72.

[2] Liu Fenghu, Zhang Binbo. Protection and Utilization of Forest Resources, Rural practical science and technology information,2012(11):38-38.

[3] Wang Weishu, Wang Shaogang. Talking about the Countermeasures of Forest Protection and Utilization from Sustainable Development - Taking Forest Biodiversity Conservation and Pest Control as an Example, Anhui Agricultural Sciences, 2015(30):126-127,129.

[4] Li Feng. Strengthen forest protection work to ensure the safety of forest resources, Farm consultant,2015(6):138.

[5] Wu Bo. Sustainable Forestry and Forest Protection, Journal of Chifeng University (Natural Science Edition), 2015(2):146-147. 